\section{Sistema integrado de produção do tabaco: saúde, trabalho e condições de vida de trabalhadores rurais no Sul do Brasil}

Integrated tobacco production: health, labor, and working conditions of tobacco farmers in Southern Brazil

Sistema integrado de producción del tabaco: salud, trabajo y condiciones de vida de trabajadores rurales en el Sur de Brasil
Deise Lisboa Riquinho ${ }^{1}$

Élida Azevedo Hennington 2

doi: 10.1590/0102-311X00072415

\title{
Resumo
}

O estudo teve por objetivo analisar o processo de produção e comercialização do tabaco no sistema integrado e as condições de vida e trabalho de fumicultores no Sul do Brasil. Foi desenvolvido estudo qualitativo, no período de dezembro de 2010 a agosto de 2011, com realização de 31 entrevistas semiestruturadas com trabalhadores rurais e informantes chave, além de observação participante. A perspectiva ergológica foi o principal referencial analítico. O sistema integrado permite à indústria controlar os valores pagos e a qualidade do fumo. O alto custo dos insumos, o endividamento, a insuficiência do seguro agrícola e a utilização intensiva da força de trabalho familiar caracterizam a produção do tabaco. Riscos de acidentes e doenças foram relacionados ao trabalho na fumicultura. $\grave{A}$ luz do dispositivo dinâmico a três polos proposto pela ergologia, o enfrentamento dos problemas exige a confrontação entre os polos do saber dos trabalhadores e o do conhecimento técnico e científico, articulados com responsabilidade ética e social.

Tabaco; Trabalhadores Rurais; Saúde Ocupacional; Condições de Trabalho

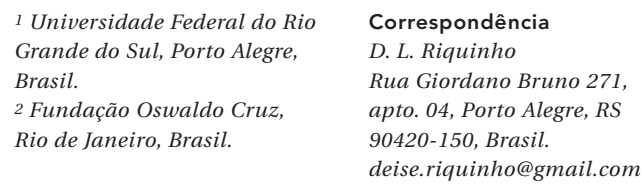

1 Universidade Federal do Rio Grande do Sul, Porto Alegre, Brasil.

2 Fundação Oswaldo Cruz Rio de Janeiro, Brasil. apto 04 Porto Alegre, RS 90420-150, Brasil. deise.riquinho@gmail.com




\section{Introdução}

O Brasil é o maior exportador de tabaco no cenário mundial e o terceiro maior produtor, perdendo a primeira e a segunda posição para China e Índia, respectivamente. Características comuns na produção de tabaco são o trabalho familiar e a forte presença do trabalho feminino e infantil 1,2. Além do risco de intoxicação provocada pelo uso de agrotóxicos, os trabalhadores também estão susceptíveis a outros problemas de saúde, tais como lesões musculoesqueléticas, doenças respiratórias, doença da folha verde do tabaco (DFVT) e acidentes típicos 3.

O cultivo do tabaco no Brasil concentra-se em pequenas propriedades rurais, e o Estado do Rio Grande do Sul contribui com cerca de $90 \%$ da produção brasileira 4,5. O incremento da produção remonta o início do século XX, tendo como marco a instalação da primeira indústria de processamento de fumo em Santa Cruz do Sul. Em 1918, a empresa Souza Cruz trouxe inovações tecnológicas no cultivo e beneficiamento e a implantação do Sistema Integrado de Produção de Tabaco (SIPT) 6 .

O SIPT estabelece um contrato entre produtor rural e a indústria do tabaco, com garantia de compra e assistência técnica correspondendo a um controle que se inicia no plantio e se estende até a entrega do produto, tendo o técnico agrícola como mediador da relação entre a empresa e o produtor de fumo, orientando as diversas etapas do cultivo 7 .

Esta pesquisa teve por objetivo analisar as condições de vida e trabalho de agricultores do tabaco em localidade rural no Estado do Rio Grande do Sul, levando-se, em consideração, aspectos macro e microssociais relacionados à inserção desses trabalhadores na cadeia produtiva do tabaco e seus significados para os próprios fumicultores, representantes da sociedade civil e da indústria.

\section{Percurso metodológico}

A pesquisa qualitativa caracteriza-se por abordar o universo de significados, motivos, aspirações, atitudes, crenças e valores. Tal abordagem metodológica compreende os fenômenos sociais como um espaço profundo para o entendimento das relações humanas 8 .

Para a ergologia, o trabalho, como atividade humana, exprime a "dialética do trabalho concreto e do trabalho abstrato", numa negociação constante entre o prescrito, a imprevisibilidade e a criação ${ }^{9}$. A situação de trabalho é lugar de um debate incessantemente reinstalado entre nor- mas antecedentes e processos de (re)normatização, da confrontação entre os saberes investidos e constituídos. A perspectiva ergológica enfatiza a compreensão do trabalho por meio de um posicionamento ético-epistemológico de humildade frente às idiossincrasias da atividade e ao patrimônio e saberes produzidos pelos trabalhadores no cotidiano 9,10,11.

A pesquisa foi realizada em localidade rural produtora de tabaco, no interior do Rio Grande do Sul, durante 90 dias não consecutivos, no período de dezembro de 2010 a agosto de 2011, de modo a oportunizar o acompanhamento de um ciclo completo de trabalho no cultivo do tabaco.

A amostra estudada foi intencional, e os entrevistados foram indicados por informantes chave da comunidade. Os sujeitos de pesquisa foram 23 famílias de agricultores, todas ligadas direta ou indiretamente à indústria do tabaco. Além das famílias, foram entrevistados oito representantes de diferentes setores da sociedade civil e três da indústria do tabaco, totalizando 31 entrevistas.

Em relação às famílias dos agricultores, buscou-se contemplar a heterogeneidade social da área pesquisada: diferentes arranjos familiares, raças/etnias e credos 12 e famílias que tinham, entre seus membros, crianças em idade escolar $\mathrm{e}$ menores de 18 anos. Os demais entrevistados foram representantes da indústria, de associações comunitárias e de pequenos produtores rurais, conforme descrito na Tabela 1.

Além das entrevistas, realizou-se observação participante com 5 das 23 famílias entrevistadas visando acompanhar o cotidiano de trabalho, suas rotinas e práticas no cultivo do tabaco. A observação participante propicia uma aproximação da realidade por meio de vivência, experiência e interpretação, num ir e vir entre o "interior" e o "exterior" dos acontecimentos, captando, por um lado, o sentido dos gestos específicos, pela empatia; de outro, situando esses significados em contextos mais amplos 13 .

Nesta pesquisa, houve predomínio de famílias vinculadas diretamente à indústria pelo sistema integrado (78\% das famílias). Havia também famílias que compravam todos os insumos em lojas agropecuárias e comercializavam para diferentes indústrias e atravessadores e ainda famílias com e sem dívida acumulada com a indústria.

Entre as famílias entrevistadas, o principal arranjo foi nuclear, formado pelo casal e filhos, seguido por apenas a presença do casal. A maioria se identificava como "brasileiro" e, a seguir, como "alemão" ou "pomerano". A religião mais referida foi a católica ( $48 \%)$ ou a luterana $(22 \%)$. A idade dos agricultores entrevistados variou entre $28 \mathrm{e}$ 
Representantes da indústria e da sociedade civil de acordo com instituição de origem, ocupação, atividade principal e idade. Rio Grande do Sul, Brasil, 2011.

\begin{tabular}{|c|c|c|c|}
\hline Instituição de origem & Ocupação * & Atividade principal & Idade (anos) \\
\hline Movimento dos Pequenos Agricultores (MPA) & Agricultor familiar polivalente & Fundador e ativista do movimento & 36 \\
\hline Associação Comunitária Local (ACL) & Agricultor familiar polivalente & Presidente da associação & 36 \\
\hline Associação de Agricultores e Apicultores (AAA) & Padre & Fundador e ativista da AAA & 73 \\
\hline Centro de Apoio ao Pequeno Agricultor (CAPA) & Técnico em enfermagem & $\begin{array}{c}\text { Educadora em saúde junto aos } \\
\text { agricultores }\end{array}$ & 46 \\
\hline União das Associações Comunitárias (UAC) & Técnico agrícola & $\begin{array}{l}\text { Apoiador da produção agroecológica e } \\
\text { do cooperativismo }\end{array}$ & 31 \\
\hline Indústria do tabaco & Técnico em contabilidade & $\begin{array}{l}\text { Instrutor da indústria 1. Responsável pela } \\
\text { captação dos agricultores no início do } \\
\text { plantio e acompanhamento da atividade, } \\
\text { como os pedidos de insumos e a } \\
\text { comercialização }\end{array}$ & 31 \\
\hline Indústria do tabaco & Técnico agrícola & Instrutor da indústria 2. Idem ao primeiro & 30 \\
\hline Indústria do tabaco & Técnico agrícola & Instrutor da indústria 3. Idem ao primeiro & 50 \\
\hline
\end{tabular}

* Classificação de acordo com a Classificação Brasileira de Ocupações (2015).

Fonte: Riquinho \& Hennington 24.

70 anos, com maior concentração etária dos 30 aos 50 anos. A média de integrantes das famílias foi de 3,4 pessoas. A maioria dos pais possuía o Ensino Fundamental incompleto, e os filhos em idade escolar frequentavam a escola, exigência da indústria do tabaco. O tempo de trabalho no cultivo do fumo variou entre 2 e 40 anos, com média de 12,3 anos e mediana de 9 anos.

$\mathrm{O}$ tratamento e a análise do material produzido a partir das entrevistas e da observação foram feitos por meio de categorização temática 8 . O projeto de pesquisa foi submetido e aprovado pelo Comitê de Ética em Pesquisa da Escola Nacional de Saúde Pública Sergio Arouca, Fundação Oswaldo Cruz (protocolo no 219/10).

\section{Resultados e discussão}

Os resultados serão apresentados a partir de dois grandes temas: O Sistema Integrado de Cultivo do Tabaco: Aspectos Macro e Microssociais Relacionados à Produção do Fumo e Condições de Trabalho, Saúde e Características da Força de Trabalho na Fumicultura.

\section{O sistema integrado de cultivo do tabaco: aspectos macro e microssociais relacionados à produção do fumo}

O SIPT é apresentado pela indústria como "um referencial no agronegócio e na agricultura familiar do Brasil" e por primar "pela sustentabilidade eco- nômica, social e ambiental e o fortalecimento da cadeia produtiva, do produtor ao cliente final" 14. Segundo o Portal do Produtor Souza Cruz ${ }^{14}$, o sistema integrado de produção de tabaco segue o princípio da mutualidade “...baseado em uma parceria técnico-comercial com produtores de tabaco, os quais têm a contratação da sua safra de tabaco com a garantia de compra de todo o volume produzido, e aonde a empresa presta Assistência Técnica especializada para a produção da safra e para o planejamento econômico, social e ambiental da propriedade. A empresa, em comum acordo com o Produtor, realiza ainda o fornecimento de insumos legais e com qualidade mínima requerida, garantindo ao mesmo o acesso a um pacote tecnológico de produção que atenda aos princípios de Boas Práticas Agronômicas e de Sustentabilidade".

Em relação ao SIPT, os discursos dos sujeitos de pesquisa deram ênfase a três questões: (1) o custo dos produtos e insumos adquiridos da indústria; (2) os problemas decorrentes da necessidade de uso do seguro das lavouras; e (3) a dívida acumulada pela dificuldade em pagar os custos da plantação ou resultante de investimentos em melhorias do cultivo e sua comercialização.

O sistema integrado, especialmente nos países periféricos, permite à indústria o controle da qualidade, volume, variedade e custos na produção do tabaco, mantendo poderes assimétricos de negociação entre as empresas e os agricultores. Estes, por sua vez, comprometem-se a seguir a orientação técnica da empresa e a entregar o 
produto final de acordo com o esquema de classificação e preço definido pela indústria 15 .

Em relação aos insumos necessários ao cultivo do tabaco, quase todos os agricultores entrevistados destacaram exigências referentes à aquisição e ao uso de produtos preconizados pela indústria para o plantio do fumo. Foram comuns as renormatizações referidas no cotidiano do trabalho como compra extra ao pedido da indústria, aprendizado coletivo no manejo do cultivo e experimentação de produtos além do previsto e orientado pelos técnicos.

Era frequente, na localidade, a compra de insumos fora do âmbito da indústria, em lojas de agropecuária ou no atacado, e o principal motivo para isso foi o preço superior pago às empresas. Ao comprar em outros estabelecimentos comerciais, o mesmo produto custava até três vezes menos. "É um desaforo, uma pouca vergonha. No ano passado, a gente fez pedido [à indústria]; a pessoa que vai na firma [indústria] é porque só tem a firma, não tem outro onde buscar" (7a família).

Sobre o aprendizado coletivo com outros agricultores, para a maioria dos entrevistados, foi uma necessidade das famílias inexperientes com o cultivo do tabaco. Nas primeiras plantações, muitos procuravam trocar dia de serviço com as famílias da comunidade ou em outras localidades vizinhas para assim apreenderem o melhor manejo da plantação. Além de buscar conhecer na prática como proceder em cada etapa de trabalho no cultivo do tabaco, eles também foram apresentados a outras maneiras de cultivar que não foram orientadas pelo instrutor da empresa:

"A gente vai aprendendo com os que já plantaram fumo, porque vinha da firma e tu botava aquilo, mas agora a gente já aprendeu com os outros, a gente já bota também ureia e essas coisas, ele [folha do tabaco] fica mais tempo verde. A gente vê também nas folhas, as folhas se espicham bem mais do que só com salito" (5a família).

Outro agricultor relatou que fez uma "experiência" com o "antibrotante prime-plus", utilizado após a quebra manual das hastes em cada pé de fumo para evitar o refloramento: "usei um pouquinho de herbicida e clorofina em cima do pé de fumo e deixei pra ver qual é o resultado. Dizem que ela seca o broto" (6a família). O Instrutor 1 constata que, em relação "ao mata broto, o produtor às vezes diminui a dosagem pra poupar, daí vêm as pragas. Não adianta me dizer que eu sei que ali ele colocou fraca a dosagem, diluiu demais, e agora vai ter um retrabalho, fazer pela segunda vez".

No trabalho, há uma distância inevitável entre o prescrito, definido pelas organizações por meio de métodos, técnicas e procedimentos $a$ priori, e o real, constituído a partir das situações concretas e suas variabilidades, dando lugar a acontecimentos complexos e a tomadas de decisões que visam preencher lacunas que surgem no aqui e agora 16 . Na brecha das normas, na porosidade do prescrito, a atividade humana comporta uma herança cultural e histórica de técnicas, de experiência das gerações passadas e da experiência pessoal, permitindo uma vivência criativa 16,17 .

Outra questão destacada nas entrevistas foi referente ao seguro contratado. A partir do pedido à indústria, é traçada uma estimativa do número de pés de fumo cultivados, e, baseada nessas informações, a Associação de Fumicultores do Brasil (AFUBRA), ligada à indústria, realiza o seguro contra perdas na lavoura, principalmente por granizo. Como definiu o Instrutor 3, "aquele número que a gente colocou e o produtor assinou tá valendo esse ano, aí deu indenizações boas".

O seguro das perdas, principalmente por queda de granizo, foi apontado, por vários trabalhadores, como um alto investimento que não compensa: paga-se todo ano e, quando precisam acionar o seguro, esse não cobre o montante do prejuízo relativo à plantação perdida. Esclarecem que o seguro é realizado com base na estimativa do pedido de compra realizada à empresa, portanto, o que excede a estimativa não é coberto pelo seguro:

"Um ano deu pedra, ficou aqui $80 \%$ de perda, nós tinha acho que uns 50 mil pés e só tinha 15 de seguro. Pagamos uns sete anos a AFUBRA, pra cair uma pedra, pra ganhar mil e poucos reais, nós não tinha tudo dentro do seguro, era pouco o que tinha seguro" (7a família).

Pelo menos, mais quatro das famílias entrevistadas revelaram perdas na lavoura sem ressarcimento por estarem fora da estimativa da indústria. Apesar do risco em ter parte do trabalho perdido, as famílias plantam a mais no intuito de obter maior lucro na comercialização do fumo, ou ainda para assegurar a reprodução da família, visto que, muitas vezes, o que está previsto na estimativa será entregue para quitar dívidas.

Foi mencionado por outras três famílias que a eficiência do seguro ocorre em caso de morte do segurado. Uma agricultora contou que, quando o esposo faleceu, tinham a dívida em 18 mil reais, e, com o uso do seguro, a dívida foi quitada. Já para outras duas famílias (10a e 18a família), o seguro do tabaco não é seguro de vida, mas "de morte": "O agricultor dá lucro pra família quando morre. Trabalha a vida inteira e só quita a divida quando morrer".

Segundo relatos, os agricultores iniciam o cultivo do tabaco já com dívida com a indústria. No primeiro ano, constroem a estrutura que será 
utilizada para armazenar e secar o tabaco. Recebem "tecedeira", "prensa", além das sementes, lonas, barbantes, agrotóxicos e demais insumos necessários ao cultivo. Pela inexperiência, normalmente, plantam pouco, por vezes, não colhem o esperado, seja por desconhecerem o ofício ou ainda pelas intempéries. Como consequência, passam a trabalhar para pagar a dívida, e, para o sustento da família, não sobra quase nada. Algumas famílias relataram que quando iniciaram o plantio não financiaram toda a estrutura necessária com a indústria, utilizaram algumas economias, evitando o endividamento.

Uma estratégia da indústria junto aos devedores é o parcelamento da dívida em longo prazo, prolongando o compromisso entre essa e os agricultores. Segundo os trabalhadores que estavam nessa situação, todo o fumo entregue para a indústria era para abater a dívida. Para que obtenham dinheiro para seu sustento e da família, vendem tabaco para atravessadores, diminuindo a quantidade entregue à indústria e aumentando a dívida por meio de juros.

Houve também queixas de que o parcelamento da dívida não é bem explicado pelos instrutores; quando firmam o acordo, entendem que não haverá juros ou um juro menor do que são notificados ao efetuarem o pagamento. Poucos foram os que referiram terem entrado na justiça contestando a dívida; apenas dois. Um deles há quatro anos e até aquele momento não havia ocorrido nenhuma audiência; e outro que, após acionar a justiça, foi procurado pelo instrutor e acabou fazendo acordo com a indústria, quitando a dívida ao vender dois dos animais usados para o trabalho.

As empresas British American Tobacco e Philip Morris, desde a década de 1990, aumentaram a eficiência da produção do tabaco por meio do maior controle e acesso a novos mercados e, assim, obtiveram maiores lucros, mantendo os trabalhadores rurais numa relação de dependência e subordinação 18 .

Segundo o representante do Movimento dos Pequenos Agricultores (MPA), movimento camponês organizado em 17 estados do Brasil e integrado à Via Campesina, a ideia disseminada de que o fumo dá lucro para o trabalhador rural constrange as pessoas que estão endividadas. Existem famílias de agricultores residindo nos paióis do fumo devido às precárias condições de habitação: "se tem uma ideia de que o fumo dá dinheiro, e dá dinheiro (para a empresa); é uma cultura muito subsidiada pelo governo, mas o ciclo de exploração das empresas com os agricultores é tão forte" (representante do MPA). Para ele, existem poucas famílias que conseguem aumentar o seu poder de compra, porém, os demais não conseguem quitar as dívidas com a indústria e, a cada ano, são taxados com mais juros:

"As famílias trabalham pelo menos 18 horas por dia, num ciclo de exploração, de dominação por parte dessas empresas. Até os contratos as pessoas assinam sem ler, o contrato ele é feito totalmente a favor da indústria, se o agricultor precisar recorrer em função do contrato é causa perdida. O contrato sempre é favorável à indústria, nunca protege o integrado" (representante do MPA).

Para o representante da União das Associações Comunitárias (UAC), organização fundada em 1988 com base na agroecologia e no associativismo de agricultores familiares do município pesquisado e região, em relação a outros cultivos, o tabaco é uma alternativa viável de renda, embora a ideia de ganho extra, às vezes, seja bastante ilusória. O que acontece é uma movimentação de grande quantidade de dinheiro durante o ano, mas o lucro final para o agricultor é pequeno, dando uma falsa impressão de que eles têm uma boa renda. Segundo o entrevistado, há cerca de 20 anos, o interior do município modificou-se, especialmente em relação ao consumo de bens, como motos, carros e máquinas agrícolas, que aumentou significativamente. Assim como cresceu também o endividamento das famílias. Observou-se ainda a deterioração da saúde dos trabalhadores: “as pessoas trabalhavam no fumo e hoje não podem trabalhar mais" (representante do Centro de Apoio ao Pequeno Agricultor - CAPA).

Segundo o representante do MPA e do fundador e ativista da Associação de Agricultores e Apicultores da região, não se conhece o número de agricultores endividados com a indústria. Mas segundo eles, apenas num escritório de advocacia do município, existiam 400 ações contra a indústria, outras já estão em fase de execução e ainda há aqueles agricultores que fazem acordo e vão plantando na esperança de, no próximo ano, sanar as dívidas. Essa última alternativa dificilmente se torna realidade: além da dívida acumulada corrigida anualmente, soma-se a dívida do ano corrente para o plantio, situação que foi exemplificada como uma "bola de neve".

Nos casos que foram julgados pelo Poder Judiciário, nota-se conservadorismo, e os pareceres são quase sempre favoráveis à indústria: "o Poder Judiciário, os próprios advogados acabam, na última hora, fazendo o jogo da indústria, é muito duro isso" (representante do MPA). Além disso, a contratação de advogados exige um gasto a mais que os agricultores, por vezes, não podem arcar. A alternativa costuma ser "o acordo com a indústria a bem de encerrar o cultivo".

O que diferencia esses agricultores endividados daqueles que quitam suas dívidas no primei- 
ro ano de plantação ou logo em seguida? Alguns já tinham dinheiro para investir, não financiaram os galpões e estufas ou pagaram parte deles. Outros parecem mais dedicados, dispostos e adaptados às características do trabalho: "se o cara não pegar uma estufa pra plantar fumo e não nanar igual uma criança pequena, ele não vai conseguir chegar lá, tem que ter muito cuidado" (21a família) - referindo-se ao cuidado e dedicação necessários ao sucesso da plantação e colheita do fumo.

Outra forma de endividamento são os investimentos que os trabalhadores fazem para melhorar as condições de trabalho. Segundo um dos agricultores, da mesma forma que se obtém dinheiro com o fumo, também se adquire dívida: "porque o cara tá sempre melhorando, quem não acompanha a evolução fica pra trás, né? O cara paga esse ano e faz divida de novo, sempre correndo atrás da máquina" (16a família).

As novas aquisições que viriam facilitar a atividade são estufas e tecedeiras elétricas que diminuem tanto o número de etapas como a força utilizada para a execução do trabalho, como também tratores e automóveis, nem sempre tão úteis ao trabalho, dada às características do local com aclives e declives íngremes, mas motivadas por apelos comerciais. De acordo com os entrevistados, instaura-se um círculo vicioso: com compras financiadas e a mudança de status ao adquirir tais bens, os agricultores assumem novas dívidas. Ao buscar pagá-las, veem a necessidade, cada vez maior, de aumentar a plantação de tabaco para pagar os financiamentos bancários.

No que tange ao processo de comercialização do produto, praticamente todas as famílias vendem parte do tabaco cultivado para o atravessador - "picareta" como eles denominam. No entanto, há duas situações distintas: aqueles agricultores que entregam o que foi estimado à empresa quando efetuado o pedido de compra e vendem o excedente da plantação; e os que não conseguem entregar o estimado para a empresa e comercializam com os "picaretas".

A prática de venda do fumo para atravessadores quando efetuada dentro da margem da indústria é conhecida e explicada por um dos instrutores da seguinte maneira: "Se o produtor vai receber seis reais ao quilo da empresa e, se há dívida, por exemplo, três reais ficam para quitar a divida e três reais de lucro. Ao vender por cinco reais ao atravessador, ele recebe o total. Nesse momento, é um bom negócio, mas, na próxima safra, a dívida dobra de valor. Mas, são poucos casos, e também quem faz isso são os mais atrasados e que menos condições de vida têm. O produtor que paga direitinho à empresa e trabalha correto, esse é o que melhor se encontra" (instrutor 1).
No discurso do instrutor, percebe-se uma desqualificação e culpabilização dos trabalhadores em dívida com a indústria, vinculando-os às piores condições de vida, com intuito de reforçar o que é propagado pelas empresas e presente no imaginário social, ou seja, os altos ganhos obtidos a partir do cultivo do tabaco pelo sistema integrado e os casos pontuais de insucesso devido a características e comportamentos individuais. Atores do conglomerado transnacional fumageiro como SINDIFUMO (Sindicato da Indústria do Fumo) e AFUBRA colaboram para reforçar a noção de que o fumo é a atividade agrícola mais rentável comparado a outros cultivos como milho e feijão, e enfatizam tratar-se de uma atividade estável, beneficiada com uma política de definição de preços e com a garantia de venda do produto final 19. No entanto, o preço pago tanto pelas empresas quanto pelos atravessadores dependerá da oferta e demanda do tabaco.

Os agricultores mencionaram também a grande expectativa, quase sempre frustrada, em relação à classificação do fumo quando é vendido à empresa: "se manda um produto de primeira, geralmente eles vão pagar de segunda". Para outro agricultor, o processo de classificação é rápido e subjetivo: "os fardos passam por esteiras que estão sempre rodando e não se tem tempo de contestar o que foi decidido". O instrutor 1 declara que "os produtores ainda não sabem classificar fumo: eles fazem uma apartação, como se diz, amarelo pra um lado e manchado pro outro, preto e verde era isso aí, mas existem 48 classes, então, ele vai ser melhor classificado lá dentro [na indústria]".

Ao documentar as características das transações entre produtores rurais e agroindústria fumageira no Rio Grande do Sul, estudo de Barreiro et al. 20 identificou que a maioria $(63,6 \%)$ dos agricultores entrevistados afirmaram se sentir prejudicados na classificação do tabaco pela indústria. Os principais motivos alegados pelas empresas para essa ocorrência, segundo os agricultores, eram a planta estar muito seca ou úmida demais.

\section{Condições de trabalho, saúde e características da força de trabalho na fumicultura}

Há o reconhecimento, por parte das famílias estudadas, dos riscos à saúde e do adoecimento como consequência do trabalho, especialmente, da relação da colheita do fumo molhado com sinais e sintomas compatíveis com a DFVT; das doenças respiratórias agravadas pela poeira das folhas secas; de acidentes por queda da estufa ou da carreta com carga de fumo e de lesões dermatológicas causadas por contato com agrotóxicos e da intoxicação associada a quadros depressivos 21 . 
Fassa et al. 22, em pesquisa realizada em São Lourenço do Sul, evidenciaram a prevalência maior de DFVT entre mulheres $(11,9 \%)$ do que entre homens (6,6\%), apontando que diferenças biológicas e a divisão social do trabalho podem explicar tais achados.

Em estudo de prevalência de distúrbios psiquiátricos menores (DPM) entre agricultores do tabaco, Faria et al. 23 inferiram a existência de associação entre DPM e intoxicações por agrotóxicos, uso de organofosforados e ocorrência da DFVT. A aplicação do teste SRQ-20 revelou que a prevalência de DPM foi de $12 \%$, sendo as mulheres mais acometidas. Presença de dívida e trabalhar como empregado ou meeiro aumentaram a chance de DPM.

Ao buscar compreender concepções dos agricultores que resistiram ou desistiram do cultivo de tabaco 24 em comunidade tradicionalmente fumicultora, observou-se que a aposentadoria de membro da família e menores extensões de terra influenciavam a decisão pelo não cultivo. Para as famílias que desistiram, o principal motivo apontado foi o endividamento: o êxito financeiro esperado e prometido pela indústria foi frustrado mediante sucessivas tentativas.

Onze por cento da população infantil mundial está em situação de trabalho, e mais da metade desse contingente (59\%) trabalha na agricultura 25. Neste estudo, observou-se a presença de trabalho infantil intrafamiliar em 8 das 23 famílias estudadas (35\%) e também a contratação de força de trabalho externa à família. As crianças estão expostas a agrotóxicos e risco de acidentes pelo uso de máquinas agrícolas. Sua imaturidade fisiológica, biológica e psicológica as tornam mais vulneráveis que os adultos aos riscos ocupacionais 24,26 . As consequências da exposição aos agentes nocivos à saúde, em alguns casos, ficará evidente somente na vida adulta com o surgimento de cânceres, infertilidade e doenças osteomusculares, dentre outros problemas 26,27.

O trabalho infantil é uma modalidade presente no cultivo do fumo, principalmente nas etapas de colheita; na organização das folhas para a cura, na qual são costuradas em varas de bambus e penduradas a uma altura de até cinco metros; $\mathrm{e}$ ainda para auxiliar na classificação e na confecção dos molhos das folhas secas. O envolvimento de menores de 18 anos no trabalho é percebido pelos agricultores como algo decorrente do interesse desses ou ainda da necessidade da família. Observou-se que os jovens, apesar de não possuírem habilitação, dirigem máquinas agrícolas como trator ou ainda operam tecedeiras elétricas, colocando, em risco, sua integridade física.

O trabalho é realizado no turno inverso à escola. No entanto, é nas férias escolares de verão que a ajuda de crianças se concentra na colheita e cura do tabaco. Os pais são alertados para possíveis flagrantes do trabalho infantil por parte da indústria: "O instrutor disse, 'vocês se cuidem com os aviões por cima da lavoura podem estar filmando"' (7a família). As crianças também se expõem indiretamente quando brincam nos galpões onde é armazenado o fumo. Enquanto os pais estão classificando ou "manocando" (fazendo os molhos), elas brincam ao redor, permanecendo próximos ao fumo e de diversos materiais como machados e máquinas de pulverizar manualmente agrotóxicos. Foram citados casos de "alergia ao fumo" em crianças.

Estudo que analisou o trabalho de crianças em áreas de cultivo do tabaco no Malauí, maior produtor de fumo da África, destacou que os vídeos produzidos e apresentados pela indústria em campanhas publicitárias negam a realidade observada e também captada em imagens da força de trabalho infantil naquela região 18 . A pobreza dos agricultores e o trabalho infantil são imagens bem diferentes daquelas propaladas na busca de legitimação e da disseminação do ideário de empresa "socialmente responsável", preocupada com o bem-estar humano e ambiental 18 .

Não é apenas no trabalho no âmbito familiar que os jovens menores de 18 anos se envolvem no cultivo do tabaco. Muitos são contratados por outras famílias para o trabalho temporário da colheita até a classificação do fumo, algumas vezes com o pagamento apenas no final da safra. A maioria dos agricultores contrata trabalhadores temporários para auxiliar a família nas diferentes etapas do cultivo. A colheita é o período de maior contratação pelo risco em perder a qualidade das folhas ao ficarem mais tempo que o necessário na lavoura.

O labutar no fumo demanda tempo e esforço intensivo do conjunto dos membros da família, diminuindo as chances de empreenderem outras atividades agrícolas e não agrícolas no meio rural 19,20. Cerca de $90 \%$ do total de trabalhadores envolvidos nas atividades de cultivo provêm da própria família, e os $10 \%$ restantes são formados por trabalhadores temporários 4 .

A rotina de trabalho dos diaristas é árdua; saem de casa antes das seis horas da manhã e retornam por volta das 22 horas. Além da alimentação restrita no local de trabalho, outro ponto negativo levantado pelas famílias foi que os diaristas ficam responsáveis pelo trabalho mais difícil, em que o terreno é irregular e há ervas daninhas espinhosas como o joá.

Uma característica que todos concordam em relação ao trabalho no fumo é a exaustão que ele provoca. As famílias afirmam que é preciso trabalhar pelo menos umas 15 horas por dia. 
Perde-se também a “liberdade", não se tem mais tempo para as reuniões sociais, especialmente no período da colheita de dezembro a março. Ambiguidade e certo conformismo e resignação foram percebidos na fala de alguns agricultores: "o fumo ele estressa, ele faz tudo de ruim", porém ainda é considerado pelas famílias que cultivam uma boa alternativa de renda.

Quando interrogados sobre qual outro cultivo gostariam de fazer que não o fumo, os agricultores mencionaram que, se tivessem o mesmo valor comercial, plantariam milho, feijão, verduras e cebola. Prefeririam cultivos que não levassem "venenos". O leite foi mencionado também como uma alternativa, mas salientaram que "o leite tá muito barato". Com um plano municipal de incentivo ao plantio de algumas frutas como morango para abastecer uma indústria local, alguns agricultores mencionaram diminuir o plantio de fumo e aderir ao novo cultivo. Outros ainda citaram o plantio de eucalipto e de acácia. Mas o que ficou evidente foi o desejo e a necessidade de cultivar algo que lhes dê retorno financeiro: "eu mudaria de plantação se os nossos governos lançassem alguma coisa que fosse compatível com a renda do fumo, caso contrário, vou ter que ir trabalhando no fumo até me aposentar" (9a família).

Para uma das entrevistadas, plantar tabaco é vantajoso dado sua resistência: "Porque o fumo aguenta, né? O fumo é muito assim, aceita, ele fica parado um pouco, mas, no momento que chove, ele reage. Resiste à seca e à chuvarada, ele vai e vai, e só no último caso mesmo, senão ele não se entrega, né?" (14a família). Essa analogia parece definir um pouco o grupo de agricultores pesquisados: são pessoas que vêm de uma história de privação, pobreza e estigma 28 , mas igualmente de resistência. Plantando fumo conseguiram algum ganho econômico, outros permanecem endividados, quase todos referem críticas ao sistema produtivo no qual estão inseridos, mas não veem saída ou alternativa melhor. Alguns parecem esperançosos, aguardando uma outra oportunidade.

Estudo de Lecours et al. 15 demonstrou que os pequenos agricultores do tabaco mostraram-se receptivos às mudanças na produção, mas políticas e programas de governo são necessários para melhorar seu acesso ao mercado de cultivos alternativos. Nesta pesquisa, identificou-se que a indústria "semeou" a ideia de um cultivo rentável e seguro em oposição à busca por culturas alternativas por parte dos agricultores da região, utilizando-se da presença dos instrutores, junto aos trabalhadores rurais, e da propaganda e influência econômica e política, junto ao Poder Público ${ }^{29}$. De acordo com Otanãez et al. 30 , em países como o Malauí, onde a indústria do tabaco exerce forte influência econômica e política sobre o governo, as tentativas em minar políticas de controle do tabaco são constantes, configurando obstáculos no desenvolvimento e na implementação de estratégias eficazes.

\section{Considerações finais}

Estudar as condições de vida e trabalho dos agricultores que produzem tabaco pelo sistema integrado em localidade rural no Sul do Brasil permitiu conhecer e compreender as relações de trabalho estabelecidas, as características da produção e o cotidiano de (re)normatizações em confronto com as normas e valores instituídos pela indústria do tabaco. A margem que os trabalhadores têm para criar e desenvolver outras experiências de trabalho é pequena, pois a indústria se utiliza de mecanismos de controle e exploração para garantir a quantidade e qualidade do produto a um custo que lhe seja vantajoso. Houve vários relatos de endividamento e de diminuição do tempo destinado ao convívio social e consequente dificuldade de organização dos trabalhadores rurais para defesa de seus direitos. Estabeleceu-se um ciclo de exploração e endividamento que gera dependência e subordinação dos trabalhadores.

As facilidades anunciadas pelo técnico agrícola ao visitar os agricultores, sensibilizando-os para aderirem ao sistema integrado foram contestadas logo após as primeiras safras. Além das questões econômicas, as dificuldades no cultivo caracterizadas pelas sucessivas etapas de trabalho com utilização intensiva de força de trabalho de todos integrantes da família, o desgaste físico, o uso de agrotóxicos no plantio e a queima de madeira para a cura do tabaco levam à ocorrência de acidentes e doenças, ocasionando impactos negativos à saúde humana e ao ambiente.

Chama-se a atenção para a necessidade de se propor políticas públicas de controle ao tabaco que deem o devido destaque à saúde dos trabalhadores rurais e à adoção de estratégias para o desenvolvimento de culturas alternativas economicamente viáveis, considerando a realidade local, a vivência e experiência dos protagonistas do trabalho, tornando-os partícipes ativos do processo. À luz da ergologia e de seu dispositivo dinâmico a três polos, a superação desse quadro de exploração e degradação da saúde poderá surgir do diálogo e confrontação entre os polos do saber dos agricultores e suas famílias, construído a partir do patrimônio e das práticas cotidianas de trabalho, e o polo dos conceitos gerados pelo conhecimento técnico e científico, articulados com responsabilidade ética e social. 


\section{Colaboradores}

D. L. Riquinho trabalhou na concepção do artigo, metodologia, pesquisa e escrita final. E. A. Hennington participou de todas as etapas do trabalho, orientando e revisando-o.

\section{Agradecimentos}

À Coordenação de Aperfeiçoamento de Pessoal de Nível Superior (Capes) pela concessão de bolsa durante estágio de doutoramento em Coimbra, Portugal.

\section{Referências}

1. Orr A. "Green gold?": burley tobacco, smallholder agriculture, and poverty alleviation in Malawi. World Dev 2000; 28:347-63.

2. McKnight RH, Spiller HA. Green tobacco sickness in children and adolescents. Public Health Rep 2005; 120:602-5.

3. Riquinho DL, Hennington EA. Health, environment and working conditions in tobacco cultivation: a review of the literature. Ciênc Saúde Coletiva $2012 ; 17: 1587-600$.

4. Associação dos Fumicultores do Brasil. Fumicultura no Brasil 2009. http://www.afubra.com.br (acessado em 17/Out/2009).

5. Deser. A cadeia produtiva do fumo. http://www. deser.org.br (acessado em 17/Out/2009).

6. Souza Cruz. Quem somos. http://www.souzacruz. com.br/group/sites/sou_7uvf24.nsf/vwPagesWe bLive/DO7V9KSX?opendocument (acessado em 29/Abr/2015).

7. Rudnicki CPS. As relações de confiança no sistema integrado de produção do tabaco (SIPT) no Rio Grande do Sul/Brasil [Tese de Doutorado]. Porto Alegre: Programa de Pós-graduação em Desenvolvimento Rural, Faculdade de Ciências Econômicas, Universidade Federal do Rio Grande do Sul; 2012.

8. Minayo MCS. O desafio do conhecimento. 10a Ed. São Paulo: Editora Hucitec; 2007.

9. Entrevista: Yvez Schwartz. Trab Educ Saúde 2006; 4:457-66.

10. Schwartz Y. Disciplina epistêmica, disciplina ergonômica: paideia e politeia. Pro-posições 2002; 13:126-49.

11. Hennington EA. Gestão dos processos de trabalho e humanização em saúde: reflexões a partir da ergologia. Rev Saúde Pública 2008; 42:555-61.

12. Gerhardt TE. Anthropologie et santé publique: approche interdisciplinaire, pauvreté, situations de vie et santé au quotidien à Paranaguá, Paraná, Brésil [Tese de Doutorado]. Bordeaux: Université de Bordeaux 2; 2000.

13. Cliford J. A experiência etnográfica: antropologia e literatura no século XX. Rio de Janeiro: Editora UFRJ; 1998.

14. Souza Cruz. Sistema integrado. https://www.pro dutorsouzacruz.com.br/conheca-o-sistema-inte grado (acessado em 29/Abr/2015).
15. Lecours N, Almeida GEG, Abdallah JM, Novotny TE. Environmental health impacts of tobacco farming: a review of the literature. Tob Control 2012; 21:191-6.

16. Brito J. Trabalho e saúde coletiva: o ponto de vista da atividade e das relações de gênero. Ciênc Saúde Coletiva 2005; 10:879-90.

17. Fígaro R. Atividade de comunicação e de trabalho. Trab Educ Saúde 2008; 6:107-45

18. Otañez MG, Glantz SA. Trafficking in tobacco farm culture: tobacco companies use of video imagery to undermine health policy. Vis Anthropol Rev 2009; 25:1-24.

19. Lima RG. Desenvolvimento e relações de trabalho na fumicultura sul-brasileira. Sociologias 2007; 9:190-225

20. Barrero GAB, Freitas CA, Ilha AS, Staduto JAR. A fumicultura no Rio Grande do Sul: uma abordagem sob a ótica da nova economia das instituições. http://www.ufsm.br/mila/clailton/publicacoes/ cientificos/fumicultura-rs.pdf (acessado em 10/ Mar/2012).

21. Riquinho DL, Hennington EA. Cultivo do tabaco no Sul do Brasil: doença da folha verde e outros agravos à saúde. Ciênc Saúde Coletiva 2014; 19:4797-808.

22. Fassa AG, Faria NMX, Meucci RD, Fiori NS, Miranda VI, Facchini LA. Green tobacco sickness among tobacco farmers in Southern Brazil. Am J Ind Med 2014; 57:223-300

23. Faria NMX, Fassa AG, Meucci RD, Fiori NS, Miranda VI. Occupational exposure to pesticides, nicotine and minor psychiatric disorders among tobacco farmers in southern Brazil. Neurotoxicology 2014; 45:347-54.

24. Riquinho DL, Hennington EA. Aderir ou resistir ao cultivo do tabaco? Histórias de trabalhadores rurais de localidade produtora no Sul do Brasil. Ciênc Saúde Coletiva 2014; 19:3981-90.

25. Organização Internacional do Trabalho. Medir o progresso na luta contra o trabalho infantil: estimativas e tendências mundiais 2000-2012. Genebra: Organização Internacional do Trabalho; 2013.

26. Fassa AG, Facchini LA, Dalll'Agnol MM, Christiani DC. Child labor and health: problems and perspectives. Int J Occup Environ Health 2000; 6: 55-62. 
27. Parker DL, Fassa AG, Scanlon TJ. Understanding the effects of child labour. In: Fassa AG, Parker DL, Scanlon TJ, editors. Child labour: a public health perspective. New York: Oxford University Press; 2010. p. 103-21.

28. Fialho MAV. Rincões de pobreza e desenvolvimento: interpretações sobre comportamento coletivo [Tese de Doutorado]. Rio de Janeiro: Curso de Pós-graduação em Desenvolvimento, Agricultura e Sociedade, Instituto de Ciências Humanas e Sociais, Universidade Federal Rural do Rio de Janeiro; 2005 .
29. Riquinho DL, Hennington EA. Diversificação agrícola em localidade rural do Sul do Brasil: reflexões e alternativas de cumprimento da ConvençãoQuadro para o controle do tabaco. Physis (Rio J.) 2014; 24:183-207.

30. Otanãez MG, Mamudu HM, Glantz SA. Tobacco companies' use of developing countries' economic reliance on tobacco to lobby against global tobacco control: the case of Malawi. Am J Public Health 2009; 99:1759-71.

\begin{abstract}
This study aimed to analyze the tobacco farming and marketing process in an integrated system and tobacco farmers' living and working conditions in Southern Brazil. A qualitative study was conducted from December 2010 to August 2011, with 31 semi-structured interviews with tobacco farmers and key informants, besides participant observation. The principal analytical reference was the ergological perspective. The integrated system allows the tobacco industry to control the amounts paid and the tobacco's quality. Tobacco growing features high cost of inputs, farmers' indebtedness, insufficient crop insurance, and intensive use of family labor. Accident and disease risks were associated with work in tobacco farming. According to the dynamic three-pole model proposed by ergology, dealing with these problems requires confronting the workers' knowledge with technical and scientific knowledge, linked with ethical and social responsibility.
\end{abstract}

Tobacco; Rural Workers; Occupational Health; Working Conditions

\section{Resumen}

El estudio tuvo por objetivo analizar el proceso de producción y comercialización del tabaco en el sistema integrado, así como las condiciones de vida y trabajo de los agricultores del tabaco en el Sur de Brasil. Se desarrolló un estudio cualitativo, durante el período de diciembre de 2010 a agosto de 2011, con la realización de 31 entrevistas semiestructuradas en trabajadores rurales e informantes clave, además de la observación participativa. La perspectiva ergológica fue el principal referente analítico. El sistema integrado permite a la industria controlar los valores pagados y la calidad del tabaco. El alto coste de los insumos, el endeudamiento, la insuficiencia del seguro agrícola y la utilización intensiva de la fuerza de trabajo familiar caracterizan la producción del tabaco. Riesgos de accidentes y enfermedades fueron relacionados con el trabajo en la agricultura del tabaco. A la luz del dispositivo dinámico de tres polos, propuesto por la ergología, la superación de los problemas exige la confrontación entre los polos del saber de los trabajadores y del conocimiento técnico y científico, articulados con la responsabilidad ética y social.

Tabaco; Trabajadores Rurales; Salud Laboral; Condiciones de Trabajo
Recebido em 06/Mai/2015

Versão final reapresentada em 24/Dez/2015 Aprovado em 22/Mar/2016 